\title{
ESCREVER OUTRA VEZ: LUTO E JOGO EM QUATRO-OLHOS, DE RENATO POMPEU ${ }^{1}$
}

\section{Miguel Conde ${ }^{2}$}

Resumo: Argumento neste ensaio que o romance Quatro-olhos (1976), de Renato Pompeu, oscila entre luto e jogo ao falar da vida durante a ditadura militar brasileira (1964-1985). Essa ambivalência pode ser compreendida como uma forma de assinalar as perdas irrecuperáveis causadas pela violência autoritária, sem deixar de buscar reinscrever no presente também um gesto de insubordinação que evite a paralisia melancólica. A escrita se define como a tentativa de "escrever outra vez" um livro apreendido pela repressão política e desde então desaparecido. No ato de "escrever outra vez", o que retorna e se repete do passado é o próprio gesto da escrita. Incapaz de recuperar o perdido e desfazer o que aconteceu, ele se assume também como gesto de invenção. As lacunas da recordação se tornam um espaço de experimentação e o luto se faz acompanhar do jogo.

Palavras-chave: Renato Pompeu; Quatro-olhos; anos 1970; literatura e ditadura; luto e jogo.

Abstract: In this essay, I argue that the novel Quatro-olhos (1976), by Renato Pompeu, alternates between mourning and play in approaching life during Brazil's military dictatorship (1964-1985). This ambivalence can be understood as a way of indicating the irreparable grievances caused by authoritarian violence, while at the same time re-inscribing in the present a gesture of insubordination that avoids melancholic immobility. Writing is defined in the novel as the attempt to "write once more" or to "write another time" ("escrever outra vez") a book seized by political repression and missing ever since. In the act of "escrever outra vez", what returns from the past is the gesture of writing itself. Incapable of retrieving what is lost and undo what has been done, this gesture incorporates a measure of invention. The gaps of remembrance become an open field for experimentation, and mourning is combined with play. Keywords: Renato Pompeu; Quatro-olhos; 1970s; literature and dictatorship; mourning and play.

\footnotetext{
1 Este artigo é uma versão adaptada de um dos capítulos da minha tese de doutorado, defendida na PUC-Rio sob orientação de Rosana Kohl Bines, a quem agradeço pelas sugestões e troca de ideias generosa ao longo dos últimos anos. 2 É Doutor em Letras pela PUC- Rio, e jornalista pela UFRJ. Atua na área de imprensa e editoração. E-mail: mbconde@ gmail.com
} 


\section{LINHAS DE FUGA}

Que um romance como Quatro-olhos não seja exatamente um livro esquecido, mas tampouco dos mais lembrados, é uma condição na qual reconhecemos, de imediato, os elementos centrais de seu enredo - uma história que expõe e tematiza a todo momento a série intermitente de lembranças e esquecimentos que a constitui. Poderíamos pensar que essa intermitência se duplica, de algum modo, na constituição um tanto irregular e obscura da fortuna crítica do romance, de maneira que a tarefa detetivesca de recolha de pistas sobre o livro parece ainda um desdobramento da trama, e somos levados a pensar nos lapsos e reminiscências de que é feita a própria história literária. Talvez fosse mais acertado dizer: qualquer história, se pensarmos que não há enredo que não demande, em sua fatura, uma composição de relevos e de apagamentos. ${ }^{3}$ Essa composição diz respeito, em Quatro-olhos, à vida durante a ditadura militar brasileira, que é tomada no livro como objeto de recordação. Nesse contexto, a exposição reiterada dos lapsos da memória se deixa ler como uma série de marcos - o apagamento se torna uma espécie às avessas de relevo, chamando atenção para aquilo que se pretenderia fazer desaparecer por meio dos recalques constitutivos do discurso oficial do governo autoritário. O movimento lacunar e intermitente da memória se contrapõe à construção maciça, monumental, dos marcos históricos (os memoriais) do Estado.

Publicado em 1976 pela editora Alfa-Omega, Quatro-olhos é o romance de estreia de Renato Pompeu, jornalista nascido em Campinas em 1941. O enredo do livro tem correspondências significativas com a vida do autor. Assim como o protagonista do romance, Pompeu foi preso durante a ditadura e esteve internado em instituições manicomiais, como se pode ler no seu livro (este, de não ficção) Memórias da loucura (1983). ${ }^{4}$ Ele ainda publicaria mais de 20 livros de ficção e não ficção até sua morte, em 2014. Nenhum deles, porém, com a mesma acolhida de sua obra de estreia. Nos primeiros anos após sua publicação, Quatro-olhos atraiu a atenção de críticos como Luiz Costa Lima, Flora Süssekind e João Luiz Lafetá. Esses primeiros leitores notavam no livro uma dimensão reflexiva que dava à sua prosa feição distinta daquela predominante nas obras de maior sucesso editorial da década de 1970, caracterizada, como se diagnosticava então, por um ímpeto de resposta a certa "demanda de real" reprimida pela ditadura militar - a ficção servindo de via indireta para um desafogo cujas formas preferenciais de consumação seriam o flerte com a linguagem jornalística ou a criação de alegorias de fácil decifração. Para resumir numa fórmula esquemática a ideia comum a esses primeiros comentários: enquanto muitos livros da época faziam da

3 Agradeço a Luciana Hidalgo a pista inicial que me levou ao livro e remeto o leitor interessado ao seu ensaio "Autoficção brasileira: influências francesas, indefinições teóricas", que pensa o livro de Pompeu dentro de uma discussão sobre autoficção.

4 Até sua morte, em 2014, Pompeu manteve em veículos diversos uma atividade regular de jornalismo político e cultural. Publicado quando o autor tinha 35 anos, Quatro-olhos foi o primeiro livro de uma obra extensa, formada por volumes de ficção, ensaio e reportagem. Embora sua produção subsequente não tenha merecido a mesma atenção despertada por esse livro de estreia, e apesar dos problemas psiquiátricos explorados ficcionalmente em Quatro-olhos e depois relatados no volume aubiográfico Memórias da loucura (1983), Pompeu construiu uma trajetória importante dentro do jornalismo brasileiro, com passagens por publicações como Jornal da Tarde, Folha de S. Paulo, Veja e Caros Amigos. 
literatura uma forma vicária de ação política, Quatro-olhos praticaria de maneira deliberada uma política da forma literária. ${ }^{5}$ Se não era o único autor a realizar então uma aposta numa "política da forma", Pompeu se destacava pela lucidez e audácia com que a realizava, e que por vezes conferia à voz idiossincrática de seu romance um tom duplamente afrontoso: hostil ao regime ditatorial, por certo, mas também pouco afeito ao dogmatismo da esquerda mais ortodoxa, com a qual entretinha uma relação atravessada de tensões. A tomada de posição do livro diante dos conflitos de então supõe uma medida de distanciamento em relação aos alinhamentos da época; apesar do que possa ter (como tem) de solidário, não se deixa confundir com uma tomada de partido. O imperativo da resistência à ditadura se faz acompanhar da desconfiança quanto aos modos vigentes de praticá-la.

Esse desalinho do livro, se pudermos dizer assim, parece com o tempo constituir um problema para sua recepção crítica, mesmo aquela mais simpática ao romance. Se o que há de melancólico no livro terá interesse para uma perspectiva crítica informada por discussões sobre as relações entre trauma, memória e narração, perspectiva essa que pode ser dita predominante no debate crítico recente sobre literatura e política na ditadura brasileira, a parcela de brincadeira e humor da dicção de Pompeu parece, desse mesmo ponto de vista, menos palatável. É que não se trata aí apenas do recurso ao humor como forma de oposição ao regime autoritário, mas de um riso que se volta também sobre a resistência à ditadura e seu fracasso. Ainda que o livro, para reiterar a volta adicional no parafuso que marca a ambivalência da obra, não deixe de ser solidário com isso que ironiza, constituindo o que proponho pensar como uma oscilação entre luto e jogo.

Quatro-olhos é uma ficção em três partes sobre a vida durante o regime militar. A primeira é uma espécie de livro de memórias extravagante e caprichoso, cujo narrador ressalta ironicamente, a todo momento, o que há em seu relato de lacunar e impreciso. As duas últimas (bem menores) são narradas em terceira pessoa, com dicção mais convencional. O protagonista do romance é um funcionário de banco que escreve um livro pondo "a nu a condição humana universal e eterna, particularizada (...) nas dimensões nacionais e de momento" (POMPEU, 1976, p. 15). Esse bancário tem uma mulher de família rica que se envolve com um grupo de oposição clandestina à ditadura militar. Ainda que haja um tanto de impostura nos encontros desse grupo, a polícia vai atrás de seus integrantes. A esposa foge e o marido bancário é preso. O livro que ele escrevia é apreendido e se perde. Depois de liberado pela polícia, ele passa a deambular pela cidade em busca do manuscrito desaparecido, até que é internado num hospital psiquiátrico. Finalmente, sai de lá resolvido a escrever outra vez esse livro que sumiu. No ordenamento engenhoso criado por Pompeu, porém, começamos a leitura pelo que seria a etapa final dessa sequência. A primeira parte do livro é ao mesmo tempo a tentativa de escrever de novo o livro desaparecido e a narração do fracasso dessa tentativa, que resulta na retrospecção lacunar da obra e da vida do narrador no período da escrita. Essa primeira parte, intitulada "Dentro", se encerra bruscamente depois que o narrador recorda, numa sequência de frases breves, sua prisão e internação. Vem a

5 A recepção inicial assegura alguma continuidade de leitura do romance durante as décadas seguintes, ao menos no meio universitário. Os trabalhos de Renato Franco, Eloésio Paulo dos Reis e Lizandro Carlos Calegari nos anos 1990 (o primeiro) e 2000 (os dois últimos), reelaboram as intuições da recepção inicial, aproximando-as de debates contemporâneos sobre trauma e narração, modernidade e fragmentação estética, psiquiatria e autoritarismo. Ver as referências na bibliografia deste texto. 
seguir a narração em terceira pessoa da vida no manicômio, intitulada "Fora". A terceira parte, intitulada "De volta", conta a saída do hospício e a decisão de tentar recuperar a obra perdida, remetendo o leitor de volta ao início do romance que ele acaba de ler.

Mais do que a exclusão do protagonista no período de sua internação, o título "Fora" indica ainda a separação que se institui na segunda parte do livro entre narração e personagem principal. Ele, que antes falava por si mesmo, será a partir daí contemplado como que por outra pessoa e designado por um nome escolhido à sua revelia. No contexto da internação, o apelido "Quatro-Olhos" sugere não apenas o aspecto físico do uso de óculos, mas ainda o apagamento da identidade singular associada ao nome individual, substituído pelo que se poderia entender como uma referência irônica a um quadro psiquiátrico de dupla personalidade. Grafado em maiúsculas, ele demarcaria mesmo, então, a transformação do nome em diagnóstico. Convertido em título da obra, porém, esse apelido assume outro sentido e um alcance maior, sugerindo uma duplicidade de perspectiva que (como veremos) atravessa todo o livro. Em vez da limitação imposta à força, o "fora" se torna a perspectiva de quem permanece de alguma forma à parte do seu meio, para assim ressaltar o que há nele de estranho e improvável. O apelido que marcava a exclusão se torna um expediente crítico, uma espécie de linha de fuga a orientar o olhar idiossincrático do livro sobre seu entorno. O "dentro" da parte inicial, portanto, é já uma espécie de "fora". A clausura do manicômio passa de episódio do enredo a princípio de composição.

II. LACUNA E INVENÇÃO

Tal como lemos na frase final do romance, que nos remete de volta ao seu início, o protagonista de Quatro-olhos resolve "escrever outra vez" o livro que se perdeu (POMPEU, 1976, p. 188). A resolução enunciada ao final da história, logo compreendemos, se realiza no romance que acabamos de ler. O livro que lemos é desde o começo um segundo livro, aquele que o narrador resolve "escrever outra vez". Essa reescritura é associada no romance a um ímpeto de resistência ao regime autoritário. Se pensarmos no contexto brasileiro de 1976, quando o livro é publicado, a aproximação entre repetição e resistência parece descabida. A esquerda foi derrotada de maneira inapelável e brutal. Que sentido poderia haver em resistir por meio de algo que se realiza "outra vez"? Parece razoável supor que essa repetição não deve ser tomada ao pé da letra, de algo que se pretenda repetir tal qual. De que maneira, então?

O livro recorda algo que a repressão autoritária arruinou e que a escrita é capaz de indicar apenas aos pedaços. Perdido o princípio de concatenação dos fragmentos, essa indicação terá algo de arbitrário, de modo que a recomposição se assumirá, ao mesmo tempo, como tentativa de invenção de algo novo. O tom rebuscado, como que numa paródia da própria aspiração literária do narrador, acentua uma inesperada dimensão humorística dessa tentativa de recuperar aquilo que sumiu. Veja-se um trecho característico:

Memória não guardo entrementes de capítulo ou trecho, apenas batem no cérebro miniaturas em que me lembra ter posto o dedo, como cabeleiras douradas numa réstia de poeira brilhante de sol ou gorgolejos estertorados de um velho a lavar a boca, rostos encardidos de pó de fábrica ou imagens de Nossa Senhora 
de manto azul cheio de estrelas. De tudo isso dei conta e dou fé, mas a maravilha marmórea que fui recortando só em pedaços a esmo me relampeja na cachola (POMPEU, 1976, p. 112).

Em Quatro-olhos, se combinam dessa maneira a recordação da vida do narrador no período em que escrevia seu primeiro livro, a citação de pedaços desconexos desse livro desaparecido e a invenção do segundo livro, que se realiza no gesto de escrever outra vez. Vida e livro, citação e invenção se misturam na trama da narração, a ponto de vida e "coisas do livro" se confundirem na escrita: "não sei se falo da vida ou de coisas do livro ou mesmo se relato a memória ou estou inventando" (POMPEU, 1976, p. 75). O compromisso com o passado se faz acompanhar por uma experiência momentânea de liberdade, que tem como condição de possibilidade esse vazio deixado por aquilo que se perdeu. A reescrita aqui não pretende restituir de maneira integral aquilo que desapareceu, tampouco "reescrever" a história de maneira revisionista ou de algum modo "desfazer" a perda. Pelo contrário, ela mantém em vista, por uma espécie de via negativa, aquilo que se perdeu. A recomposição do manuscrito desaparecido é inviável, e não apenas por razões práticas, mas pela própria lógica de elaboração do relato. A condição de existência do segundo livro, aquele que lemos, é justamente que esse primeiro livro ao qual ele se refere não possa ser recuperado, o que define o livro que lemos como um projeto paradoxal, apontando o tempo todo para alguma coisa que fica de fora do seu horizonte - se o primeiro livro fosse recuperável, o segundo livro, aquele que lemos, perderia sua razão de ser. Podemos ver nesse paradoxo uma forma de assinalar, na fatura do livro, o que há de irrevogável nesses sumiços do livro e da esposa, metonímia de todas as mortes e desaparecimentos do período. Tampouco o livro perdido está de todo desaparecido, porém. Em contraponto à ideia de um passado que se deveria deixar para trás, definitivamente "enterrado", como pretendia o regime ditatorial e defendem ainda hoje os apólogos de uma enganosa forma de "perdão" (como se fosse possível perdoar o que nunca foi reconhecido como um agravo), em Quatro-olhos o passado reverbera a todo momento sob a forma da citação. Parciais, inconclusivas, as citações falam de algo desaparecido, mas não de todo arruinado. Uma constituição dupla que é bem evocada por Georg Otte em seu comentário sobre a citação e sua relação com as ideias de vestígio e de rememoração na obra de Walter Benjamin:

Estes vestígios, as "ruínas da história", não são apenas sinais do desaparecimento dos acontecimentos, mas, metonimicamente, também da sua sobrevivência. Dependendo do ponto de vista, o vestígio, como testemunho material de algum objeto ausente, sinaliza tanto a perda deste objeto quanto a possibilidade de sua evocação por um sujeito (OTTE, 1996, p. 216).

Em sua aproximação entre vida e "coisas do livro", o que se realiza "outra vez" em Quatro-olhos é o gesto da escrita, que assinala a todo momento a falta daquilo que desapareceu, ao mesmo tempo em que faz dela ocasião para criar algo novo. O passado não retorna tal qual, mas nesses fragmentos que, removidos de seu contexto, aproximam rememoração, citação e invenção. Ainda aqui, próximo ao que escreve Otte, a propósito da obra de Benja- 
min: "a rememoração não é um procedimento conservador no sentido de uma preservação do passado, uma vez que não existe um 'passado em si', mas apenas um passado visto com os olhos do presente" (OTTE, 1996, p. 2014).

Ao tomar os vestígios daquilo que se perdeu como ocasião para a aproximação entre citação e invenção no gesto de escrever "outra vez", Quatro-olhos permite que se pense um outro registro possível daquilo que se tem chamado de literatura pós-ditatorial. Pois no livro, em vez de implicar uma dimensão apenas traumática ou o trabalho doloroso do luto, o passado da violência ditatorial é recuperado por meio de vestígios que conduzem a uma prática anárquica de escrita. Essa força ainda em aberto do passado, que permite tomá-lo como a ocasião para escrever "outra vez", está ligada à sobrevivência dos vestígios do livro desaparecido. Seria possível, por isso, relacioná-la à leitura proposta por Susana Draper sobre o interesse no contexto pós-ditatorial daquilo que ela chama, a partir de Benjamin, de "afterlife". ${ }^{6}$ Por meio desta noção, Draper elabora uma alternativa à ênfase predominante, nos estudos sobre a memória do passado pós-ditatorial, nas figuras do luto, da melancolia e do trauma, buscando investigar práticas de rememoração que procuram atualizar algo de promessas pretéritas malogradas, não realizadas, de insubordinação:

O termo "sobrevivência" ["afterlife"] adquire o sentido de um modo de experimentar os ecos de um passado que está perdido para a história mas que tem o potencial de ser ouvido e tornado legível. É uma possibilidade perdida que mantém aberta a promessa daquilo que não pôde acontecer (DRAPER, 2012, p. 6, tradução minha).

A reverberação do passado no presente, sugere o historiador francês Georges Didi-Huberman, está ligada na obra de Benjamin a uma concepção do tempo histórico que tem correspondências importantes com a teoria freudiana da memória. Benjamin estaria interessado em pensar um "inconsciente do tempo", que borraria as fronteiras entre diferentes momentos históricos. Assim concebido, o passado não guarda "fatos objetivos", mas "fatos da memória", que interpelam o presente sob a forma de "rastros" impondo uma "tarefa da recordação" (DIDI-HUBERMAN, 2015 [2000]). Não seria algo semelhante a esses "rastros", em seu teor inconsciente, que se deveria pensar para compreender a narração lacunar de Quatro-olhos ("Memória não guardo entrementes de capítulo ou trecho"), que faz da recordação algo que se apresenta em "miniaturas" que "batem no cérebro" e "pedaços a esmo" que "relampejam na cachola"? Nas "batidas" e "relampejos" irregulares dessas "miniaturas" e "pedaços a esmo", é a própria narração que se faz aos pedaços, em fragmentos, para se construir segundo o ritmo intermitente da memória.

6 No ensaio "A tarefa do tradutor" (1921), Benjamin usa os termos “Überleben” e "Fortleben", para os quais Susana Kampff Lages adota as traduções "sobrevida" ou "sobrevivência", no primeiro caso, e "pervivência" no segundo, utilizando um neologismo cunhado por Haroldo de Campos. Na convoluta N das Passagens, Benjamin usa o termo "Nachleben", traduzido por Irene Aron na edição brasileira coordenada por Willi Bolle e Olgária Matos como "vida posterior". Cf. BENJAMIN, Walter. Escritos sobre mito e linguagem e Passagens. 


\section{ALEGRIA E MELANCOLIA}

Num ensaio sobre Em liberdade (1981) incluído em seu livro Alegorias da derrota (2003), Idelber Avelar propõe que esse livro de Silviano Santiago demanda a compreensão de um paradoxo, "o paradoxo de uma alegria melancólica". Os termos desse paradoxo, no entanto, se assemelham mais a um meio-termo, de acordo com a seguinte fórmula: a alegria na melancolia atestaria que "ainda não fomos narcotizados pela pilha de catástrofes a ponto de tomá-las como naturais", enquanto a melancolia na alegria demarcaria um limite a evitar "que a alegria caia na felicidade complacente própria dos que são cegos à catástrofe". A afirmação disjuntiva do paradoxo dá lugar à conciliação, estabelecendo uma justa-medida da escrita pós-ditatorial. Isso acontece porque a alegria é reduzida aí a um afeto subsidiário, de segunda mão - "a alegria que deriva de que ainda nos melancolizemos ante a barbárie política” (AVELAR, 2003, p. 188). Para fazer justiça ao que há de ambivalente em Quatro-olhos, seria preciso desfazer essa subordinação, pensar uma alegria que não seja apenas uma espécie de comprazimento reflexivo com o fato de que ainda sejamos sensíveis à catástrofe, mas um gesto criativo, de afirmação, que, sem negar a barbárie, se coloca, "outra vez", a questão do que fazer diante dela. Em contraste com a ênfase de Avelar sobre o luto no contexto pós-ditatorial, poderíamos lembrar a interpretação da alegoria proposta por Jeanne Marie Gagnebin, que sublinha a oscilação contraditória entre jogo e luto como algo próprio ao alegórico no pensamento de Walter Benjamin:

A linguagem alegórica extrai sua profusão de duas fontes que se juntam num mesmo rio de imagens: da tristeza, do luto provocado pela ausência de um referente último; da liberdade lúdica do jogo que tal ausência acarreta para quem ousa inventar novas leis transitórias e novos sentidos efêmeros (GAGNEBIN, 2011, p. 38).

Em Quatro-olhos, o escrever outra vez se dá sob a forma da citação, por meio de numerosas referências a trechos do livro perdido, aquele que não podemos ler. São citações indiretas, no entanto, precedidas por cláusulas como "meu livro tratava de", "havia uma cena", "lembro de ter escrito sobre". Aquilo que é citado não retorna como tal, em sua formulação original, mas segundo uma releitura empreendida pela memória do narrador. $\mathrm{O}$ luto por aquilo que desapareceu se torna também ocasião para a invenção no gesto de "escrever outra vez", que alude à lacuna daquilo que foi perdido, mas cria em seu lugar algo de diverso, na "outra vez" que não se realiza tal qual a primeira. Ao mesmo tempo em que indicam algo que falta, tais citações tomam alguma liberdade em relação àquilo que está ausente. Arrancadas do contexto de que faziam parte, apartadas de qualquer nexo narrativo, uma série de imagens avulsas serão manipuladas numa espécie de jogo. Aquilo que parecia perdido ganha aí outro uso, a ponto de a própria experiência da perda ser evocada na forma da brincadeira.

Mais ou menos dos 16 aos 29 anos passei no mínimo três a quatro horas todos os dias, com exceção de um ou outro sábado e de certa segunda-feira, escrevendo não me lembro bem se um romance ou um livro de crônicas (POMPEU, 1976, p. 15).

Literatura e Autoritarismo, Santa Maria, n. 31: A experiência do confinamento, jan.-jun. 2018, p. 53-67. - ISSN 1679-849X 
Desde essa notável frase de abertura, Quatro-olhos é um livro em que se associam, de maneira íntima, ironia e recordação. O esquecimento não é apenas elipse, ausência, mas também matéria que o narrador exibe (e encena?) com desfaçatez, o que confere ao relato um ar de brincadeira ou embuste. Inquieta, a narração parece indicar que aquilo que é dito não é bem ainda o que se quer dizer, como se a loquacidade ostensiva funcionasse como um mecanismo compensatório daquilo que fica de fora do relato, um excesso resultante da elisão. Ou ainda, seguindo de perto a letra do texto: um excesso feito de elisões, excesso de faltas. Os menores detalhes podem assim dar ocasião a digressões extensas, como se fosse possível encontrar sempre algo mais a dizer a respeito de cada coisa, a ponto de o formato de uma cebola largada sobre a mesa ser tomado como um símbolo do infinito:

Em certo momento a narrativa tresandou a tratar de uma cebola. De tão antigo e nobre vegetal, reverenciado pelos partidários dos costumes sãos, desfolhava eu finas folhas translúcidas cor-de-prata, deixada opaca a esfera símbolo do infinito, delicada casca vermelha quebradiça a um lado largada, verdes efêmeros escapando pelas nervuras esbranquiçadas dos círculos cortados. Estava a cebola posta em seu canto sobre um prato à mesa, enquanto em derredor se desenrolava instrutiva conversação, mas eu, num aventureirismo técnico de velho conhecedor literário, discutia mais a cebola com a faca ao lado num rebrilho de metal com vegetal, do que o tráfico de palavras (POMPEU, 1976, p. 53).

As prioridades se invertem: as nervuras da cebola se tornam mais importantes do que a "instrutiva conversação", o livro se demora sobre detalhes acessórios, que passam a constituir sua matéria primordial. Essas divagações são às vezes associadas pelo narrador ao seu alheamento em relação ao engajamento da esposa na época da escrita do primeiro livro. Uma indiferença da qual ele se dirá arrependido:

Agora me interrogo sobre por que minha mulher nunca aparecia no livro; creio pertencer ela ao mundo externo, sem que eu nunca conseguisse internalizá-la, embora ela me penetrasse por dentro da pele e sua carne estivesse tão próxima. Ela não fazia parte dos retalhos de imagens que eu ia juntando em novas formas no livro. Não era como o rastro de pássaro no ar, um risco de vento, nem como os tijolos em massa reunidos numa construção em andamento (POMPEU, 1976, p. 124).

Se a mulher e seus companheiros de luta política constam do segundo livro, ao menos em sua ausência, ainda aí não haverá de fato, porém, uma adesão do narrador à escala de prioridades que determinaria uma revisão dos assuntos realmente importantes sobre os quais a narrativa deveria se demorar. Pelo contrário: em sua recordação entrecortada, Quatro-olhos reinscreve no presente da escrita esse interesse inesperado pelos detalhes. Menos do que em alheamento ou alienação política, seria melhor falar numa indistinção anárquica, que recusa e desfaz as hierarquias habituais entre principal e acessório para se interessar pelos "cacos" ao redor: 
Ali mesmo na sala ia eu juntando cacos no escrito, a trajetória de uma formiga no pátio da escola com um resto de folha à mandíbula, um sonho em que eu flutuava sobre a cidade no ar muito frio e com as costas arranhadas pela vidraça do sair voando do quarto em que dormia, um conjunto de reflexões sobre coxas apenas adivinhadas que engrouvinhavam a saia que as vestia (POMPEU, 1976, p. 114).

Escrever "outra vez" é também recolher esses cacos, que não se deixam articular numa narrativa íntegra, mas se acumulam numa montagem confusa e desordenada, desnorteante, cheia de lacunas. Em vez de uma sequência narrativa convencional, essa dicção lacunar produz algo que se assemelha a um amontoado de imagens. Nele, as coisas mais díspares se aproximam: "Houve capítulo sobre ombros" (POMPEU, 1976, p. 56) ;"Por vezes falava de cabelos gelatinados por fixador, grudentos em nuca e testa” (POMPEU, 1976, p. 58); “Creio que no livro falei alguma vez de cenouras, brilhos carnudos laranja a alongar-se finos" (POMPEU, 1976, p. 75); “creio ter feito referência vadia a pernas moças, a brilhar em contracapa de revista num anúncio de cigarro" (POMPEU, 1976, p. 76); "Em certo momento, falei da moça abandonada, que ocupou um capítulo" (POMPEU, 1976, p. 78); "Falava de chocolate quente em noite de frio, de filhos embrulhados em panos de flanela, de cabelos soltos a esvoaçar ao vento numa praia de luz fosca, de trevos encrencados em autoestrada, de folhas secas presas num livro velho" etc (POMPEU, 1976, p. 81). Do jornalismo, influência decisiva para tantas ficções da época, pode-se tirar uma analogia que ajuda a caracterizar a prática de escrita que aí se realiza. Enquanto em vários romances de então o trabalho investigativo do repórter assumiria feição heroica - sua busca pela verdade servindo de figura modelar (e nem tão velada) de resistência à ditadura - a peculiar dicção do narrador de Pompeu poderia ser aproximada da atividade pouco romântica do copidesque, aquele profissional encarregado de reescrever o texto alheio. Não é irrelevante que em sua trajetória profissional o autor tenha exercido por muitos anos essa função, em razão das limitações que os delírios esquizofrênicos impunham ao seu trabalho jornalístico, como ele recorda em Memórias da loucura: "Eu não me atrevia a fazer entrevistas e ser repórter porque não tinha certeza de não misturar coisas imaginárias com as coisas realmente vistas e ouvidas" (POMPEU, 1983, p. 17). Mais importante do que essa nota biográfica, porém, é a centralidade que as ideias de reescritura e citação assumem no romance, a ponto de produzirem uma indistinção entre a vida e as "coisas do livro". A memória torna-se uma atividade intertextual. O narrador de Quatro-olhos é um copidesque liberado de seus compromissos profissionais de concisão, clareza e urgência. Não importa dar a palavra final, que aproxima a copidescagem da tesoura do censor. Tampouco há uma corrida contra o relógio do fechamento da edição. A copidescagem se torna, inversamente, uma prática reiterada de abertura e adiamento. Seu compromisso não é com a letra do texto, mas com as permutações que permitem, apesar de tudo, voltar "outra vez" à escrita. 


\section{O FUTURO DO PASSADO}

Um dos vários meta-comentários feitos ao longo do romance, entre a piada e o manifesto, expondo os dilemas da escrita, é a esse respeito particularmente significativo: "Incapaz de defender o futuro, defendo o futuro do passado (...) Defendo um futuro que o passado devia ter tido - e que não teve" (POMPEU, 1983, p. 28). Pode-se ter, de início, a impressão de que o narrador assume aí um compromisso com os projetos políticos derrotados pela ditadura militar: "defendo um futuro que o passado devia ter tido", ele escreve. Ou seja, os planos revolucionários da esposa. No entanto, o final da frase demarca o reconhecimento de que esse futuro do pretérito não se efetivou: "devia ter tido - e que não teve". Este futuro é, portanto, também algo de passado, e a defesa que o narrador realiza é inseparável desse reconhecimento. Não se trata de uma reedição da luta pretérita, mas de algo mais complicado: como escrever em nome de algo que sequer se realizou? O que se pode recuperar daquilo que permaneceu apenas como projeto ou desejo?

Talvez se possa responder: o que retorna é o desejo, mais do que seu objeto anterior (ou seja, o projeto). Trata-se então de evocar esses projetos derrotados (ou fracassados) sem, no entanto, subscrevê-los. Pode-se dizer: buscar o desaparecido não para reencontrá-lo tal como antes do desaparecimento, o que seria impossível, mas para impedir que ele permaneça na sombra do esquecimento ou do anonimato. Esse gesto está associado, no livro, a um ímpeto de crítica ao presente. Ou seja, o luto é inseparável da afirmação do desejo de que o presente seja outro. Se até aqui tenho dado ênfase a tudo que há no livro de oscilante, cabe observar: em nome desse passado, ele condenará de maneira inapelável o presente - "Muito embora creia não ser possível condenar o presente em nome do passado, pois o passado já passou e o presente está passando" (...) "não encontro em meu coração outro recurso". O narrador se declara, nesse momento, incapaz de "condenar em nome do que virá" (POMPEU, 1983, p. 28).

O combate realizado em nome do passado e de seu futuro não realizado - em nome do futuro do pretérito, e não do futuro do presente - faz pensar numa das passagens do último texto de Walter Benjamin, "Sobre o conceito da História" (BENJAMIN, 2013 [1942]). Nesse escrito derradeiro, Benjamin associa aquilo que chama de "as melhores forças" das classes trabalhadoras ao "ódio" e ao "espírito de sacrifício". Tais afetos não se alimentam "do ideal dos descendentes livres" - ou seja, de uma ideia de futuro - mas "da imagem dos antepassados oprimidos" - portanto, de uma imagem do passado.

O passado aparece aí como um repositório de forças indispensáveis à disputa política, que é pensada nos termos de um combate. Cabe perguntar: que tipo de combate? Seja lá como queiramos julgar o narrador do livro, parece certo que ele está longe de ser um herói. Se a recordação confere ao passado uma força mobilizadora, escapando ao simples ressentimento ou à melancolia, a ironia solapa a tentação inversa, de apresentar essa mobilização em chave épica, fazendo um panteão monumental dos heróis da esquerda.

O narrador do livro fala de um "eu" que ele mesmo não é mais. Sua antiga indiferença às questões políticas é narrada em tom de crítica. Isso não impede, porém, que algo desse outro "eu" perdido se infiltre no presente da narração, instaurando uma convivência insólita entre as duas personas, o artista alienado e o memorialista de luto. Os saltos de um re- 
gistro a outro dão ao livro certo ar de falta de compromisso, pois nunca se pode ter certeza se o que é dito numa linha não vai ser desdito na linha seguinte. A recordação fragmentária instaura um humor irônico e absurdo. As passagens recordadas formam uma sequência de disparates, no que o próprio narrador denomina "retalhos de imagens" (POMPEU, 1983, p. 124). Essa experiência de um passado que não se pode recuperar nem deixar para trás, e que insiste em se fazer presente na forma do "retalho", tem um efeito inesperado. Ao manipular os fragmentos daquilo que se perdeu, o narrador experimenta aproximações incomuns, se aproxima do nonsense e sublinha o que há de improvável na composição. O luto se faz acompanhar de um jogo, aquele possível em meio às ruínas.

\section{REFERÊNCIAS}

ARRIGUCCI JR, David. et al. “Jornal, realismo, alegoria: o romance brasileiro recente”. In: Achados e perdidos. São Paulo: Polis, 1979.

AVELAR, Idelber. Alegorias da derrota. A ficção pós-ditatorial e o trabalho do luto na América Latina. Belo Horizonte: UFMG, 2003.

BENJAMIN, Walter. "Sobre o conceito da História”. In: O anjo da história. Belo Horizonte: Autêntica, 2013. Organização e tradução de João Barrento.

BENJAMIN, Walter. Escritos sobre mito e linguagem. São Paulo: Duas Cidades e Editora 34, 2011. Organização, apresentação e notas de Jeanne Marie Gagnebin. Tradução de Susana Kampff Lages e Ernani Chaves.

BENJAMIN, Walter. Passagens. Belo Horizonte e São Paulo: Editora da UFMG e Imprensa Oficial do Estado de São Paulo, 2006. Organização de Willi Bolle, com a colaboração de Olgária Chain Féres Matos. Tradução do alemão de Irene Aron e do francês de Cleonice Paes Barreto Mourão.

CALEGARI, Lizandro Carlos. A literatura contra o autoritarismo: a desordem social como princípio de fragmentação na ficção brasileira pós-64. Santa Maria: UFSM, 2008. Tese de doutorado.

COSTA LIMA, Luiz: "Réquiem para a aquarela brasileira”. In: Dispersa demanda. Rio de Janeiro: Francisco Alves, 1981.

DIDI-HUBERMAN, Georges. Diante do tempo. História da arte e anacronismo das imagens. Belo Horizonte: Editora UFMG, 2015 [2000]. Tradução de Vera Casa Nova e Márcia Arbex.

DRAPER, Susana. Afterlives of confinement. Spatial transitions in Postdictatorship Latin America. Pittsburgh: University of Pittsburgh Press, 2012.

FRANCO, Renato. “O romance de resistência nos anos 1970”. XXI LASA CONGRESS 1998, Chicago, EUA. 
GAGNEBIN, Jeanne Marie. História e narração em Walter Benjamin. São Paulo: Perspectiva, 2011 [1999].

HIDALGO, Luciana. "Autoficção brasileira: influências francesas, indefinições teóricas". Alea, Rio de Janeiro, v. 15/1, pp. 218-231, jan.-jun. 2013.

OTTE, Georg. "Rememoração e citação em Walter Benjamin". In: Aletria: Revista de estudos de literatura. Belo Horizonte, v. 4, pp. 211-223, outubro de 1996.

POMPEU, Renato. Quatro-olhos. São Paulo: Alfa-Omega, 1976.

POMPEU, Renato. Memórias da loucura. São Paulo: Alfa-Omega, 1983.

REIS, Eloésio Paulo dos. Literatura e loucura: O escritor no hospício em três romances dos anos 70. Campinas: Unicamp, 2004. Tese de doutorado.

SÜSSEKIND, Flora. Tal Brasil, qual romance? Rio de Janeiro: Achiamé, 1984. 